\title{
Dietary Fat Increases High Density Lipoprotein (HDL) Levels Both by Increasing the Transport Rates and Decreasing the Fractional Catabolic Rates of HDL Cholesterol Ester and Apolipoprotein (Apo) A-I
}

\author{
Presentation of a New Animal Model and Mechanistic Studies \\ in Human Apo A-I Transgenic and Control Mice
}

\author{
Tony Hayek, " Yasushi Ito, * Neal Azrolan, * Roy B. Verdery, ${ }^{*}$ Katriina Aalto-Setälä, * Annemarie Walsh, * and Jan L. Breslow * \\ *Laboratory of Biochemical Genetics and Metabolism, The Rockefeller University, New York 10021-6399; \\ and ${ }^{\ddagger}$ Arizona Center on Aging, Tucson, Arizona 85719
}

\begin{abstract}
In humans, diets high in saturated fat and cholesterol raise HDL-cholesterol (HDL-C) levels. To explore the mechanism, we have devised a mouse model that mimics the human situation. In this model, HuAITg and control mice were studied on low fat ( $9 \%$ cal)-low cholesterol $(57 \mathrm{mg} / 1,000 \mathrm{kcal})$ (chow) and high fat (41\% cal)-high cholesterol $(437 \mathrm{mg} / 1,000 \mathrm{kcal})$ (milk-fat based) diets. The mice responded to increased dietary fat by increasing both HDL-C and apo A-I levels, with a greater increase in HDL-C levels. This was compatible with an increase in HDL size observed by nondenaturing gradient gel electrophoresis. Turnover studies with doubly labeled HDL showed that dietary fat both increased the transport rate (TR) and decreased the fractional catabolic rate of HDL cholesterol ester (CE) and apo A-I, with the largest effect on HDL CE TR. The latter suggested that dietary fat increases reverse cholesterol transport through the HDL pathway, perhaps as an adaptation to the metabolic load of a high fat diet. The increase in apo A-I TR by dietary fat was confirmed by experiments showing increased apo A-I secretion from primary hepatocytes isolated from animals on the high fat diet. The increased apo A-I production was not associated with any increase in hepatic or intestinal apo A-I mRNA, suggesting that the mechanism of the dietary fat effect was posttranscriptional, involving either increased translatability of the apo A-I mRNA or less intracellular apo A-I degradation. The dietary fat-induced decrease in HDL CE and apo A-I fractional catabolic rate may have been caused by the increase in HDL particle size, as was suggested by our previous studies in humans. In summary, a mouse model has been developed and experiments performed to better understand the paradoxical HDL-raising effect of a high fat diet. ( $J$. Clin. Invest. 1993. 91:1665-1671.) Key words: high density lipoprotein • high fat $\bullet$ turnover $\bullet$ particle size distribution • metabolism • apolipoprotein A-I • diet responsiveness
\end{abstract}

Address correspondence to Jan L. Breslow, M.D., Laboratory of Biochemical Genetics and Metabolism, The Rockefeller University, 1230 York Ave., New York, NY 10021-6399.

Received for publication 31 May 1992 and in revised form 23 October 1992.

J. Clin. Invest.

(C) The American Society for Clinical Investigation, Inc.

0021-9738/93/04/1665/07 \$2.00

Volume 91, April 1993, 1665-1671

\section{Introduction}

In most societies today, there is a well-known inverse correlation between coronary heart disease risk and HDL cholesterol (HDL-C $)^{1}$ levels (1-3). However, paradoxically, diets high in saturated fat and cholesterol, which increase atherosclerosis risk, raise HDL-C levels (4-9). To explore the mechanism for this phenomenon and perhaps gain greater insight into the role of HDL in heart disease, in a previous human metabolic study (9), we measured the turnover of the major HDL apolipoproteins, apo A-I and apo A-II, in 13 subjects consuming low fat ( $9 \%$ calories)-low cholesterol $(40 \mathrm{mg} / 1,000 \mathrm{kcal})$ and high fat (42\% calories)-high cholesterol $(215 \mathrm{mg} / 1,000 \mathrm{kcal})$ diets. The dietary fat challenge increased HDL-C $40 \%$, apo A-I $30 \%$ (both $P<0.001$ ), with no change in apo A-II levels. The turnover studies indicated a $17 \%$ increase in apo A-I transport rate (TR) and a $10 \%$ decrease in apo A-I fractional catabolic rate (FCR). Individual changes in HDL-C levels correlated with changes in apo A-I TR $(r=0.79, P<0.001)$ but not FCR $(r$ $=-0.04)$. This study suggested that dietary fat both increases the TR and decreases the FCR of apo A-I with perhaps a larger effect on the TR (9).

Since clinical studies do not allow further examination of how dietary fat influences apo A-I metabolism nor do they permit studies of HDL CE metabolism, in the current study, to pursue these questions, an animal model was created. Mice were used because of the availability of human apo A-I transgenic (HuAITg) lines $(10,11)$. These animals express significant amounts of human apo A-I in plasma, and for reasons not yet understood, they have greatly diminished mouse apo A-I levels (11-13). Accompanying this exchange of human for mouse apo A-I is a change from normal mouse HDL, which has a single major size distribution of HDL particles to humanlike HDL characterized by two or more major size distributions, principally $\mathrm{HDL}_{2 \mathrm{~b}}$ and $\mathrm{HDL}_{3 \mathrm{a}}(11-13)$. Thus, HuAITg mice might be a better model in which to study the dietary fat-HDL relationship.

As in the human metabolic study, mice were fed low fat ( $9 \%$ calories)-low cholesterol ( $57 \mathrm{mg} / 1,000 \mathrm{kcal}$ ) and high fat ( $41 \%$ calories), high cholesterol ( $437 \mathrm{mg} / 1,000 \mathrm{kcal}$ ) diets. In contrast to previously used high fat-high cholesterol diets that have lowered HDL-C and apo A-I levels in some strains of mice

1. Abbreviations used in this paper: $\mathrm{CE}$, cholesterol ester; FCR, fractional catabolic rate; GGE, gradient gel electrophoresis; HDL-C, HDL cholesterol; TR, transport rate. 
(14), the dietary fat challenge raised HDL-C and apo A-I levels, as observed in humans (4-9), allowing detailed examination of the mechanism(s) for this dietary fat effect in the animal model.

\section{Methods}

Transgenic mice. One line of human apo A-I transgenic mice (line 179), which was previously described (10), was used. The line was created by microinjecting an $11.5-\mathrm{kb}$ human apo A-I genomic fragment extending from $5.5 \mathrm{~kb} 5$ ' to $3.8 \mathrm{~kb} \mathrm{3}$ ' to the gene into $\mathrm{F} 1$ (C57BL/ $6 \mathrm{~J} \times \mathrm{CBA} / \mathrm{J}$ ) fertilized eggs. The founder mouse was mated to $\mathrm{F} 1 \mathrm{~s}$ of the same genetic background, and transgenic offspring were similarly mated. Comparisons in metabolic studies were with nontransgenic litter mates. Whereas the endogenous mouse apo A-I gene is expressed equally in the liver and intestine, the human apo A-I transgene is expressed only in the liver in this line of mice (10).

Diets. The mice were fed two contrasting diets. The low fat-low cholesterol diet was rodent chow (no. 5001; Ralston-Purina, St. Louis, MO). Its composition was (wt/wt): $4.5 \%$ fat, $59.8 \%$ carbohydrate, $23.4 \%$ protein, $5.0 \%$ fiber, $7.3 \%$ minerals, added vitamins $\mathrm{A}, \mathrm{D}$, and $\mathrm{E}$, and $0.02 \%$ cholesterol. Fats provided $9 \%$ of the calories, equally divided between saturated, monounsaturated, and polyunsaturated fats (kindly analyzed by Dr. Lisa Hudgins [15]), and there was $57 \mathrm{mg} /$ $1,000 \mathrm{kcal}$ of cholesterol. The high fat-high cholesterol diet was a milk fat based diet made for us (TD\#88137; Teklad Premier Laboratory Diets, Madison, WI). Its composition was (wt/wt): $21.2 \%$ fat, $49.1 \%$ carbohydrate, $19.8 \%$ protein, $5.0 \%$ fiber, $3.5 \%$ minerals, $0.4 \% \mathrm{CaCO}_{3}$, $1 \%$ vitamin mix, $0.004 \%$ antioxidant, and $0.2 \%$ cholesterol. Fats provided $41 \%$ of the calories, with $27 \%$ saturated, $12 \%$ monounsaturated, and $2 \%$ polyunsaturated, and there was $437 \mathrm{mg} / 1,000 \mathrm{kcal}$ of cholesterol. The cholesterol content of both diets was verified by gas chromatography. The fat content of the high fat-high cholesterol diet corresponds to the 50th percentile of American dietary intake observed in the Lipid Research Clinic Study and the 75th percentile of intake in the most recent National Health and Nutrition Examination Survey $(16,17)$.

Blood and tissue sampling protocol. Animals were placed in metabolic cages in animal rooms with alternating 12-h periods of light ( 7 a.m. -7 p.m.) and dark ( 7 p.m.-7 a.m.) with ad lib access to food and water. For blood sampling, mice were fasted overnight and the animals bled the next morning from the retroorbital plexus under methoxyflurane anesthesia. Blood was collected into a tube containing $6 \mu \mathrm{l}$ of EDTA $(0.5 \mathrm{M})$. Plasma was separated by centrifugation at $1,875 \mathrm{~g}$ for $15 \mathrm{~min}$ and kept at $4^{\circ} \mathrm{C}$ until analysis. Where indicated, fasted animals were subjected to liver biopsy through a midline incision under anesthesia with $2.5 \%$ Avertin $(0.02 \mathrm{ml} / \mathrm{g}$ body wt $)$. The liver tissue ( $50-100$ $\mathrm{mg}$ ) was frozen immediately in liquid nitrogen and stored at $-70^{\circ} \mathrm{C}$. At the end of each diet study, the animals were fasted overnight and anesthetized with $2.5 \%$ Avertin. The liver and total small intestine were obtained, frozen immediately, and stored as above.

Plasma HDL-C and apo A-I analyses. HDL-C levels were determined by measuring cholesterol either in the $d>1.063 \mathrm{~g} / \mathrm{ml}$ infranatant after airfuge ultracentrifugation, as previously described (10), or in the supernatant after precipitation of the other lipoproteins by dextran sulfate. The latter involved adding $11 \mu \mathrm{l}$ of dextran sulfate $\mathrm{Mg}^{+2}$ solution $(10 \mathrm{~g} /$ liter dextran sulfate, $\mathrm{mol} \mathrm{wt} 50,000,0.5 \mathrm{~mol} /$ liter $\mathrm{Mg}^{+2}$, buffered (no. 352-3; Sigma Immunochemicals, St. Louis, MO) to $60 \mu$ l of plasma. This procedure was validated by immunochemical methods by showing that it did not precipitate apo A-I, but precipitated $96 \%$ of apo B. The particular method used for HDL-C determination in a given experiment is indicated. Cholesterol was determined enzymatically using reagents (no. 236691; Boehringer). In the HDL fraction, free cholesterol and total cholesterol (after saponification) were measured by gas chromatography with coprostanol as an internal standard. The cholesterol ester (CE) was taken as the difference between the two. Mouse apo A-I levels were quantified by rocket immunoelectrophoresis using a polyclonal anti-mouse apo A-I antibody prepared in cyno- molgus monkeys (generously provided by Dr. George Melchior, Upjohn Company, Kalamazoo, MI) as previously described $(10,12,13)$. Human apo A-I levels were measured by enzyme-linked immunoabsorbent assay using a polyclonal goat anti-human apo A-I antibody, which was a gift from Dr. Peter Herbert, Miriam Hospital (Providence, $\mathrm{RI})$ as previously described $(10,18)$. There was essentially no crossspecies reactivity for either antibody.

In vivo HDL turnover studies. HDL doubly labeled in its apo A-I and cholesteryl ester moieties was prepared as previously described (12, 13, 19-21). We previously showed that human and mouse apo A-I have the same rate of disappearance from the plasma of HuAITg and control mice (10). Therefore, turnover studies in the current experiments were done only with radioiodinated human apo A-I. HDL CE was labeled with $\left[{ }^{3} \mathrm{H}\right.$ ] cholesteryl oleoyl ether that had been dissolved in intralipid and transferred into HDL by CETP from $d>1.25 \mathrm{~g} / \mathrm{ml}$ rabbit plasma $(12,13,21)$. Mice were injected in the femoral vein with doubly labeled HDL (2-4 $\mu$ g of [ ${ }^{125}$ I] human apo A-I and 100,000$200,000 \mathrm{dpm}$ of $\left[{ }^{3} \mathrm{H}\right]$ cholesteryl oleoyl ether). The injected HDL mass was $<5 \%$ of the mouse HDL pool $(12,21)$. Blood $(50 \mu \mathrm{l})$ was taken from the retroorbital plexus under methoxyflurane anesthesia at 10 min, $90 \mathrm{~min}, 3 \mathrm{~h}, 8 \mathrm{~h}$, and $28 \mathrm{~h}$ for determination of radioactivity. The FCRs for apo A-I and HDL CE were calculated from the plasma decay curves of $\left[{ }^{125} \mathrm{I}\right]$ apo $\mathrm{A}-\mathrm{I}$ and $\left[{ }^{3} \mathrm{H}\right]$ cholesteryl oleoyl ether assuming a two-pool model by the Matthews method (22).

HDL particle size determination. HDL particle size distribution was determined by nondenaturing gradient gel electrophoresis (GGE) as previously described $(23,24)$. In a $175-\mu \mathrm{l}$ airfuge tube, $40 \mu \mathrm{l}$ of plasma was adjusted to density $1.21 \mathrm{~g} / \mathrm{ml}$ with $1.35 \mathrm{~g} / \mathrm{ml} \mathrm{KBr}$, and this was overlayered with $50 \mu \mathrm{l}$ of $1.21 \mathrm{~g} / \mathrm{ml} \mathrm{KBr}(1 \mathrm{mM}$ EDTA $)$. After ultracentrifugation at $100,000 \mathrm{~g}$ for $5 \mathrm{~h}$ (Airfuge, Beckman), $30 \mu \mathrm{l}$ was aspirated from the top of the tube and electrophoresed in nondenaturing 4-30\% polyacrylamide gradient gels (PAA 4/30; Pharmacia LKB, Piscataway, NJ) for $20 \mathrm{~min}$ at $70 \mathrm{~V}$ and then for $18-24 \mathrm{~h}$ at $125 \mathrm{~V}$. Gels were fixed, stained, destained, and scanned as previously described (24). Scans were analyzed by Gaussian modeling and Stokes' radii of HDL particles determined by comparing migration distances to those of proteins of known size (24).

In vitro apo A-I production. Apo A-I production was determined in primary hepatocytes from mice fed the low fat-low cholesterol and high fat-high cholesterol diets. Mice were weaned and then fed the diets for 4 wk. Animals were fasted overnight, anesthetized with $5 \%$ sodium pentobarbital, and hepatocytes prepared by minor modifications of the method described by Sparks (25). The portal vein was cannulated and the liver was first perfused with a calcium-free isotonic buffer at $37^{\circ} \mathrm{C}$ for $10-15 \mathrm{~min}$, and then perfused with a buffer containing $5 \mathrm{~m} \mathrm{M} \mathrm{CaCl}_{2}$ and $\mathbf{0 . 0 7 5 \%}$ (wt/vol) collagenase (Boehringer Mannheim) for $30 \mathrm{~min}$. After perfusion, the liver was gently disaggregated and the cells suspended in calcium-free buffer. The cells were washed with PBS and M199 (Sigma Immunochemicals), and dead cells were separated by centrifugation in $50 \%$ colloidal polyvinyl pyrrolidine-coated silica (percoll; Sigma Immunochemicals). Cell viability was assured by trypan blue staining and 500,000 live cells were plated on a $35-\mathrm{mm}$ plate coated with poly-D-lysine. The culture medium was changed after $4 \mathrm{~h}$ incubation at $37^{\circ} \mathrm{C}$. The next day, the cells were washed with $\mathrm{M} 199$, and fresh culture medium containing $100 \mu \mathrm{Ci} / \mathrm{ml}$ of $\left[{ }^{35} \mathrm{~S}\right]$ methionine was added and the cells incubated for $40,60,90$, and $120 \mathrm{~min}$ at $37^{\circ} \mathrm{C}$. After incubation, the medium was removed, the cells were washed twice with PBS, and then solubilized with $0.1 \mathrm{~N} \mathrm{NaOH}$. Cell protein was determined using the detergent-compatible protein assay (Bio Rad Laboratories, Richmond, CA) using BSA as a standard. $300 \mu \mathrm{l}$ medium from each plate was used for immunoprecipitation using a mono-specific goat anti-human apo A-I antibody that does not bind to mouse apo A-I. Briefly, an equal volume of protein-A binding buffer (Pierce Chemical Co., Rockford, IL) was mixed with the medium in a $1.5-\mathrm{ml}$ Eppendorf tube. To this was added $15 \mu \mathrm{l}$ anti-human A-I antisera, and the tubes were placed on a rocker at $4^{\circ} \mathrm{C}$ for $16 \mathrm{~h}$. The next day, $15 \mu \mathrm{l}$ of rabbit anti-goat IgG (Pierce Chemical Co.) was added and the tubes were incubated for $2 \mathrm{~h}$ at $4^{\circ} \mathrm{C}$. $60 \mu \mathrm{l}$ of a $20 \%$ protein-A Sepharose 
suspension (Sigma Immunochemicals) was then added, and the tubes were incubated an additional $2 \mathrm{~h}$. The protein-A pellets were then washed by centrifugation three times, each with $500 \mu$ l binding buffer. After washing, a 26-gauge needle was used to aspirate the last of the buffer from the protein-A pellets by placing it directly into the resin. To the washed pellets was added $60 \mu$ l of nonreducing SDS sample buffer (containing no $\beta$-mercaptoethanol). The samples were boiled and centrifuged, and then $50 \mu \mathrm{l}$ of the supernatant was loaded onto a $12 \%$ SDS-PAGE (29:1 acrylamide/ Bis) gel (6\% stacking gel), and electrophoresed at $100 \mathrm{~V}$ for $5 \mathrm{~h}$. The gels were then stained with Coomassie blue, destained, then treated with $\mathrm{EN}^{3} \mathrm{HANCE}$ (New England Nuclear, Boston, MA), dried, and exposed to Kodak XAR film. After fluorography, the gel regions corresponding to apo A-I (27 kD) was excised, solubilized, and counted (26).

Quantitation of apo A-I $m R N A$ levels. Human and mouse hepatic and mouse intestinal apo A-I mRNA abundance was measured using the solution hybridization RNase protection method previously described (27). RNA was isolated by the method of Chomczynski and Sacchi (28). $5 \mu \mathrm{g}$ of total RNA was hybridized in solution to each riboprobe, and the RNase protected fragments collected on glass-fiber filters and counted (27). Background values for the human riboprobe using mouse hepatic RNA and for the mouse riboprobe using HepG2 cell (human) RNA were each $<0.3 \%$ of the total ${ }^{32} \mathrm{P}$-labeled probe input.

Statistical analysis. The Student's paired $t$ test was used to compare values in animals before and after the diet. An unpaired Student's $t$ test was used to compare values in groups of animals fed different diets. Statistical significance was defined as $P<0.05$. Results are presented as mean \pm SE.

\section{Results}

The effect of the high fat-high cholesterol diet on HDL-C and apo A-I levels in the mouse was determined as follows: 10-15wk-old male HuAITg mice and nontransgenic litter mates were fed the high fat-high cholesterol diet for $5 \mathrm{wk}$ and another group of HuAITg mice were kept on the low fat-low cholesterol diet for the same time period. Feedings were adjusted three times weekly based on measured food consumption to insure equal intake among the three groups of animals throughout the 5 -wk study period. From the beginning to the end of the experiment, in the HuAITg mice the high fat-high cholesterol diet increased HDL-C 65\%, human apo A-I $41 \%$, and mouse apo
A-I $48 \%$. In the control mice, the high fat-high cholesterol diet increased HDL-C 53\% and mouse apo A-I 24\%. There were no changes in HDL-C or apo A-I levels in the HuAITg mice maintained on the low fat-low cholesterol diet during the experimental period (Table I). Thus, mice exposed to a high fat-high cholesterol diet respond by increasing HDL-C and apo A-I with a greater increase in HDL-C levels.

The mice were then used to explore the mechanism of the dietary fat effect on HDL. HuAITg and control male mice of 12-16 wk of age were fed either the low fat-low cholesterol or high fat-high cholesterol diet for 4 wk and an HDL turnover study was performed. HDL was doubly labeled with [ $\left.{ }^{125} \mathrm{I}\right]$ apo A-I and $\left[{ }^{3} \mathrm{H}\right]$ cholesteryl oleyl ether, injected intravenously, and the disappearance of plasma radioactivity was measured. The Matthews method was used to calculate HDL CE FCR and apo A-I FCR; these multiplied by the pool sizes (as reflected by the plasma concentration of HDL CE and total apo A-I, respectively) estimated the TRs as summarized in Table II. In HuAITg mice the high fat-high cholesterol diet decreased the HDL CE FCR (28\%) and the apo A-I FCR (26\%) and increased the HDL CE TR (61\%) and apo A-I TR (30\%). In control mice, the high fat-high cholesterol diet decreased the HDL CE FCR (25\%) and apo A-I FCR (24\%) and increased the HDL CE TR (47\%) and apo A-I TR (25\%). Both HuAITg and control mice responded to the high fat diet by decreasing HDL CE and apo A-I FCR and increasing their TRs, with the effect on TR greater than on FCR for HDL CE. The dietary effect on FCR was equal for HDL CE and apo A-I, but its effect on TR was greater for HDL CE than apo A-I.

GGE was then used to study the effect of the high fat-high cholesterol diet on HDL particle size distribution. On the low fat-low cholesterol diet, HuAITg mouse HDL consists primarily of two distinct HDL subpopulations with particle diameters of 11.0 and $9.3 \mathrm{~nm}$, corresponding to human $\mathrm{HDL}_{2 b}$ and $\mathrm{HDL}_{3 \mathrm{a}}$. After the high fat-high cholesterol diet, there is an increase mainly in the $\mathrm{HDL}_{2 \mathrm{~b}}$ and even larger $\mathrm{HDL}$ subfractions (Fig. 1 A). On the low fat-low cholesterol diet, control mouse HDL consists primarily of a single size population with a particle diameter of $9.8 \mathrm{~nm}$. After the high fat-high cholesterol diet, the HDL size distribution still seems to show one major peak, but the peak is broadened and skewed to larger particle diame-

Table I. Effects of Diet on HDL Cholesterol and Apo A-I Levels

\begin{tabular}{|c|c|c|c|c|c|c|c|c|c|}
\hline \multirow[b]{2}{*}{ Mice } & \multicolumn{3}{|c|}{ HDL-C* } & \multicolumn{3}{|c|}{ Human Apo A-I } & \multicolumn{3}{|c|}{ Mouse Apo A-I } \\
\hline & Before & After & $\begin{array}{l}\text { Percent } \\
\text { increase }\end{array}$ & Before & After & $\begin{array}{l}\text { Percent } \\
\text { increase }\end{array}$ & Before & After & $\begin{array}{l}\text { Percent } \\
\text { increase }\end{array}$ \\
\hline & & $m g / d l$ & & & $m g / d l$ & & & $m g / d l$ & \\
\hline \multicolumn{10}{|l|}{ HuAITg $(n=5)$} \\
\hline $\begin{array}{l}\text { Low } \rightarrow \text { high fat diet } \\
\text { Controls }(n=6)\end{array}$ & $103 \pm 7$ & $170 \pm 16^{1}$ & $65 \%$ & $244 \pm 7$ & $345 \pm 16^{\S}$ & $41 \%$ & $33 \pm 8$ & $49 \pm 6^{11}$ & $48 \%$ \\
\hline $\begin{array}{l}\text { Low } \rightarrow \text { high fat diet } \\
\text { HuAITg }(n=6)\end{array}$ & $51 \pm 2$ & $78 \pm 3^{\prime}$ & $53 \%$ & - & - & - & $200 \pm 15$ & $248 \pm 20^{\ddagger}$ & $24 \%$ \\
\hline Low $\rightarrow$ low fat diet & $89 \pm 4$ & $87 \pm 5$ & - & $233 \pm 24$ & $233 \pm 24$ & - & $27 \pm 3$ & $27 \pm 4$ & - \\
\hline
\end{tabular}

${ }^{*}$ HDL-C levels were determined by measuring cholesterol in the $d>1.063 \mathrm{~g} / \mathrm{ml}$ infranatant after airfuge ultracentrifugation.

${ }^{\ddagger} P=0.059$

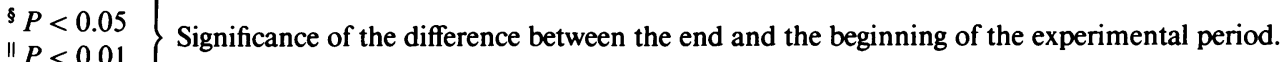

' $P<0.005$ 
Table II. Effects of Diet on HDL Metabolism

\begin{tabular}{|c|c|c|c|c|c|c|}
\hline Mice & HDL-C* & HDL CE FCR & HDL CE TR & Apo A-I & Apo A-I FCR & Apo A-I TR \\
\hline & $m g / d l$ & pools $/ h$ & $U$ & $m g / d l$ & pools $/ h$ & $U$ \\
\hline \multicolumn{7}{|l|}{ HuAITg $(n=5)$} \\
\hline Chow diet & $103 \pm 7$ & $0.110 \pm 0.003$ & $8.4 \pm 0.7$ & $326 \pm 20$ & $0.106 \pm 0.009$ & $34.4 \pm 3.5$ \\
\hline \multicolumn{7}{|l|}{ HuAITg $(n=5)$} \\
\hline High fat diet & $220 \pm 25^{\S}$ & $0.079 \pm 0.009^{\ddagger}$ & $13.5 \pm 0.2^{\S}$ & $570 \pm 40^{\S}$ & $0.078 \pm 0.008^{\ddagger}$ & $44.3 \pm 4.6^{\ddagger}$ \\
\hline \multicolumn{7}{|l|}{ Control $(n=3)$} \\
\hline Chow diet & $54 \pm 3$ & $0.182 \pm 0.009$ & $7.3 \pm 0.2$ & $168 \pm 12$ & $0.105 \pm 0.005$ & $17.6 \pm 1.1$ \\
\hline \multicolumn{7}{|l|}{ Control $(n=3)$} \\
\hline High fat diet & $103 \pm 5^{11}$ & $0.137 \pm 0.005^{\ddagger}$ & $10.7 \pm 0.8^{\S}$ & $275 \pm 5^{\S}$ & $0.079 \pm 0.003^{\S}$ & $21.8 \pm 0.1^{\ddagger}$ \\
\hline
\end{tabular}

* HDL-C levels were determined by measuring cholesterol in the supernatant after precipitation of the other lipoproteins by dextran sulfate.

${ }^{\ddagger} P<0.05$

$\left.{ }^{\S} P<0.005\right\}$ compared to the chow diet.

" $P<0.001\}$

ters (Fig. $1 A$ ). The patterns obtained by GGE analysis for several HuAITg mice on low fat-low cholesterol $(n=6)$ and high fat-high cholesterol $(n=5)$ diets were scanned individually and analyzed by Gaussian modeling (24). The results for each group of animals were averaged and the data were pre-

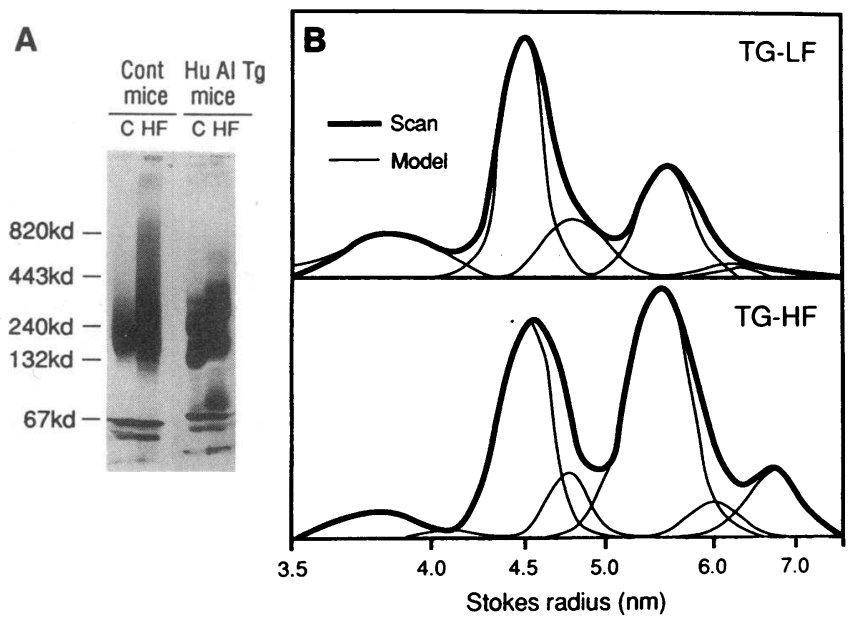

Figure 1. The effects of the high fat diet on HDL particle size distribution. $(A)$ Native gradient gel electrophoretogram (4-30\%) of 30 $\mu \mathrm{l}$ of $d<1.21 \mathrm{~g} / \mathrm{ml}$ fraction prepared from control or HuAITg plasma on low fat-low cholesterol or high fat-high cholesterol diets. As can be seen, control mouse HDL on the low fat-low cholesterol diet consists primarily of a single size population. After the high fat-high cholesterol diet the pattern is similar, but the peak is broadened and skewed to larger particle diameters. HuAITg HDL on the low fat-low cholesterol diet consists primarily of two distinct HDL subpopulations. After the high fat-high cholesterol diet, the pattern is similar, but there is an increase mainly in the larger HDL subfractions. Molecular mass markers are indicated on the left hand side of the figure. $(B)$ Shows a composite scan of native gradient gel electrophoretogram (4-30\%) of $30 \mu \mathrm{l}$ of $d<1.21 \mathrm{~g} / \mathrm{ml}$ fraction prepared from HuAITg mice $(n=6)$ on the low fat-low cholesterol diet and HuAITg mice $(n=5)$ on the high fat-high cholesterol diet. Gels were scanned individually and analyzed by Gaussian modeling. Results from each group of animals were averaged. As can be seen, the high fat-high cholesterol diet caused a relative increase only in the HDL subfractions of mean particle diameter of $\geq 11 \mathrm{~nm}$. sented in Fig. $1 \mathrm{~B}$. It can be seen that the high fat-high cholesterol diet caused a relative increase only in the HDL subfractions of mean particle diameter $\geq 11.0 \mathrm{~nm}$. Thus, a high fathigh cholesterol diet increases HDL size in both HuAITg and control mice, which is compatible with the greater increase in HDL-C compared to apo A-I, as shown in Tables I and II.

The HDL turnover studies showed that the high fat-high cholesterol diet increased the apo A-I TR. In the HuAITg mice human apo A-I is only synthesized in the liver, suggesting that this increase in apo A-I TR was caused by an increase in hepatic secretion of apo A-I. To confirm this, primary hepatocytes from HuAITg mice fed low fat-low cholesterol or high fat-high cholesterol diets were studied in an in vitro labeling experiment. As shown in Fig. 2, radiolabeled human apo A-I was secreted $40 \%$ faster from hepatocytes prepared from the animals on the high fat-high cholesterol diet relative to those prepared from animals on the low fat-low cholesterol diet. A similar effect was observed for mouse apo A-I secretion (data not shown ). Thus, a high fat-high cholesterol diet increases apo A-I secretion from the liver.

The mechanism for increased hepatic apo A-I secretion was explored further. Liver and intestinal apo A-I mRNA levels were quantified by solution hybridization/RNase protection assay in the HuAITg and control mice on the low fat-low cholesterol and high fat-high cholesterol diets. As shown in Table III, the high fat-high cholesterol diet had no significant effect on hepatic (human or mouse) or intestinal (mouse) apo A-I mRNA levels. Thus, dietary fat appears to exert its effect on apo A-I production at a posttranscriptional level. It is also noteworthy that hepatic and intestinal mouse apo A-I mRNA levels are comparable in HuAITg and control mice, in spite of the large reduction in plasma mouse apo A-I levels in the transgenic animals.

\section{Discussion}

Diets high in saturated fat and cholesterol increase the risk of coronary heart disease in humans, yet they raise HDL-C levels (4-9). To study this paradoxical phenomenon a mouse model was created. In this model, animals were studied on a low fatlow cholesterol chow diet and a high fat-high cholesterol Western type diet and dietary fat was shown to increase HDL-C 


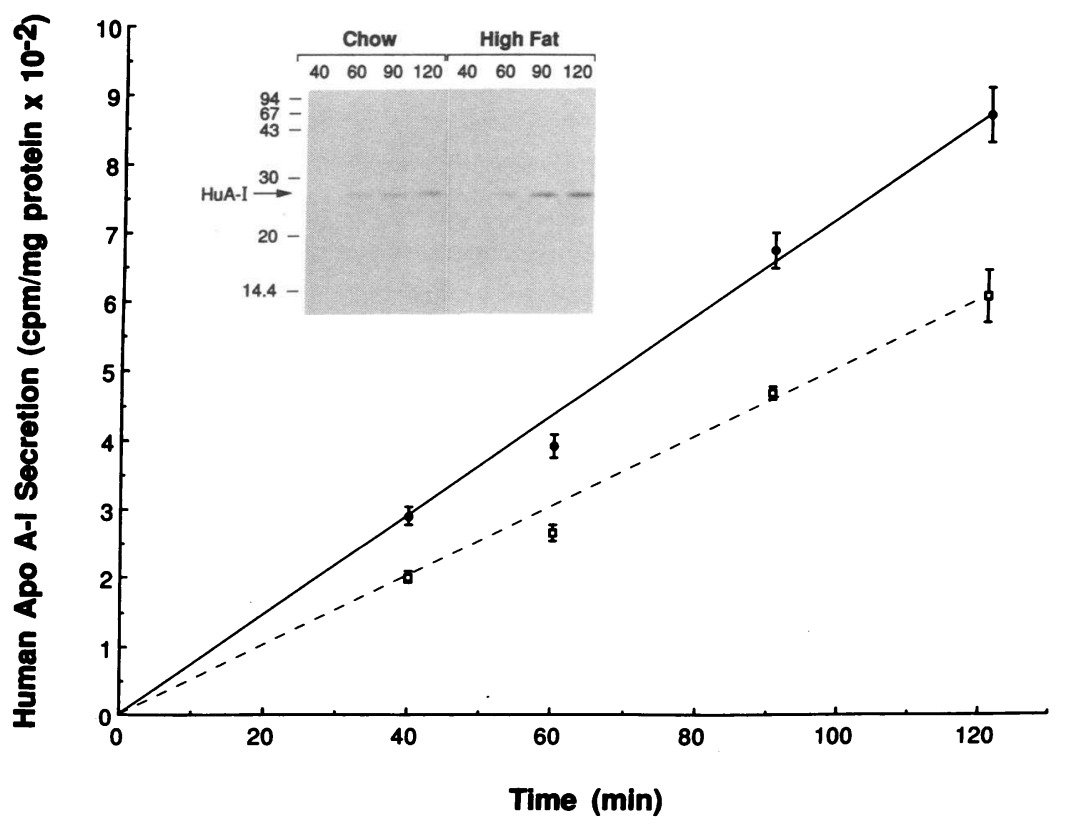

Figure 2. Effect of the high fat diet on human apo A-I secretion from transgenic mouse primary hepatocytes. HuAITg mice were fed a high fat-high cholesterol diet or a low fat-low cholesterol diet for 4 wk. Primary mouse hepatocytes were then prepared from these animals as described in Methods. These cells were incubated with serum-free medium containing 100 $\mu \mathrm{Ci} / \mathrm{ml}\left[{ }^{35} \mathrm{~S}\right]$ methionine for the indicated times. An aliquot of conditioned medium from each plate was then immunoprecipitated using an anti-human apo A-I antibody that specifically recognizes only human apo A-I. The immuno-complex was washed and subjected to SDS-PAGE analysis. Gels were then dried and autofluorographed. A representative gel film is shown in the inset. Regions on each gel that corresponded to the apo A-I bands (inset) were excised from the gel and subjected to scintillation counting. Three different gels, each derived from three different sets of dishes were used in each analysis. The experiment shown was performed several (three) times with similar results. Error bars represent SEM $(n=3)$.

levels as it does in humans (4-9). Metabolic turnover studies indicated that the high fat-high cholesterol diet decreased the FCR and increased the TR of HDL CE. The dietary effect was greatest on the HDL CE TR ( 60\% increase). This is a novel observation that may have significant implications, since HDL is thought to be involved in reverse cholesterol transport (1-3, $29,30)$. The current study suggests that the dietary fat-induced increase in HDL-C levels may be an adaptive mechanism reflecting the need for increased flux (HDL CE TR) through the HDL pathway required by the metabolic load of a high fat-high cholesterol diet. In our previous metabolic study in humans, HDL-C levels increased $40 \%$ when switching from a 10 to a $40 \%$ fat diet (9). However, there was a wide range of HDL-C response, from 7 to $68 \%$. It would have been fascinating to observe whether this range of responses of HDL-C levels correlates with differences among people in their ability to increase the flux of HDL CE (HDL CE TR). Humans who fail to respond adequately to a dietary challenge by raising their HDL-C

Table III. Effects of Diet on Hepatic and Intestinal Apo A-I mRNA Levels

\begin{tabular}{|c|c|c|c|c|c|}
\hline \multirow[b]{3}{*}{ Mice } & \multirow{2}{*}{\multicolumn{2}{|c|}{$\begin{array}{c}\begin{array}{c}\text { Human Apo A-I } \\
\text { mRNA }\end{array} \\
\text { Liver }\end{array}$}} & \multicolumn{3}{|c|}{ Mouse Apo A-I mRNA } \\
\hline & & & \multicolumn{2}{|c|}{ Liver } & \multirow{2}{*}{$\frac{\text { Intestine }}{\text { After }}$} \\
\hline & Before & After & Before & After & \\
\hline & \multicolumn{2}{|c|}{$p g / \mu g$ total $R N A$} & \multicolumn{3}{|c|}{$p g / \mu g$ total $R N A$} \\
\hline \multicolumn{6}{|l|}{ HuAITg $(n=5)$} \\
\hline $\begin{array}{c}\text { High fat diet } \\
\text { Controls }(n=6)\end{array}$ & \multicolumn{4}{|c|}{ Controls $(n=6)$} & $43 \pm 4$ \\
\hline $\begin{array}{c}\text { High fat diet } \\
\text { HuAITg }(n=6)\end{array}$ & - & - & $51 \pm 3$ & $56 \pm 5$ & $48 \pm 5$ \\
\hline Low fat diet & $250 \pm 3$ & $240 \pm 15$ & $50 \pm 1$ & $50 \pm 2$ & $52 \pm 5$ \\
\hline
\end{tabular}

There were no significant differences in hepatic apo A-I mRNA before and after the diet, nor were there any differences in intestinal apo A-I mRNA between HuAITg mice on high fat and low fat diets. levels and HDL CE TR may be at increased risk of atherosclerosis. Unfortunately, it has not been possible to easily measure HDL CE turnover in humans to study this question (31).

In the mouse model the high fat-high cholesterol diet compared to the low fat-low cholesterol diet was also shown to increase apo A-I levels, decrease apo A-I FCR and increase apo A-I TR. These results are quite comparable to those we previously obtained in humans with a similar dietary change (9). Other clinical investigators, utilizing different dietary protocols, have had different results. Blum studied three females on an extremely low fat liquid formula diet and on a high fat diet, and found a $62 \%$ increase in HDL-C levels, which he ascribed to a $32 \%$ decrease in HDL apolipoprotein FCR (6). Shepherd studied four males on a $40 \%$ fat intake of a polyunsaturated/saturated fat ratio of 4 and 0.25 , and found a $48 \%$ increase in HDL-C accounted for by a $35 \%$ increase in apo A-I TR (7). In animal studies, Quig reported in rabbits that a sixfold increase in saturated fat intake was associated with a twofold increase in HDL apolipoprotein TR without any change in FCR (32). Sorci-Thomas has reported in nonhuman primates on a high cholesterol diet that a change in the polyunsaturated/saturated fat ratio from 2.2 to 0.3 caused a $19 \%$ increase in apo A-I levels associated with a $23 \%$ increase in hepatic synthesis of apo A-I and a $28 \%$ increase in hepatic apo A-I mRNA, with no change in intestinal apo A-I mRNA (33). Thus, our own studies in humans and mice and those of others pretty consistently indicate a major effect of dietary fat on the apo A-I TR.

The measurement of apo A-I TR by turnover studies suggests that dietary fat increases hepatic or intestinal production of apo A-I. The line of HuAITg mice used in these experiments produces human apo A-I only in the liver (10). Since dietary fat caused an equal percent increase of human and mouse apo A-I in these mice, it suggests that the effect is exerted mainly on hepatic apo A-I production. Increased hepatic production of apo A-I was corroborated by in vitro labeling studies in which primary liver cell cultures from animals fed the high fat-high cholesterol diet showed increased apo A-I secretion. Srivastava et al. (34) have also shown, using liver slices, that the hepatic production of mouse apo A-I is increased in mice fed a high 
fat-high cholesterol diet. To further localize how dietary fat is acting, apo A-I mRNA levels were measured in tissues from animals on the two contrasting diets and no differences were found. Thus, the effect of dietary fat on apo A-I production is posttranscriptional and could involve increased translatability of the apo A-I mRNA or decreased intracellular degradation of the apo A-I protein. Go et al. have shown increased translatability of rat intestinal apo A-I mRNA with chronic feeding of $2 \%$ cholesterol and $0.1 \%$ propylthiouracil (35). Davis and others have shown that apo B secretion from hepatocytes is regulated by changes in intracellular degradation (36). Further studies will be necessary to determine exactly the mechanism of the dietary fat effect on apo A-I production.

In humans, a high fat diet causes an increase in the HDL-C to apo A-I ratio and an increase in HDL size $(4-9,37)$. This also occurred in both the HuAITg and control mice, as shown by chemical analysis and gradient gel electrophoresis. In previous studies in humans, we showed that apo A-I FCR was inversely correlated with HDL size and in a multivariate model HDL size was the best predictor of apo A-I FCR of all the relevant variables tested $(38,39)$. Thus, in the mouse model the effect of dietary fat on apo A-I and even HDL CE FCR might be mediated by the change in HDL size caused by the diet. It has been suggested that large HDL particles are less easily catabolized, such as through glomerular filtration of apo A-I or liver uptake of HDL particles (40), and this may account for the decrease in FCR.

Previous fat feeding studies in mice have involved toxic diets, such as ones containing $1.25 \%$ cholesterol, $15 \%$ fat, and the unusual constituent $0.5 \%$ cholic acid $(14,35,41)$. These diets did not increase HDL-C levels, but rather produced a strain-dependent decrease in HDL-C levels. This is contrary to what one sees in humans placed on a high fat diet and raises questions about the relevance of such diets to the human experience. The current manuscript presents a high fat mouse diet that mimics the human experience and has allowed examination of the mechanism whereby dietary fat influences HDL metabolism.

\section{Acknowledgments}

The authors would like to thank Dr. Tova Chajek-Shaul for her expert consultation and for her help in performing some of the turnover studies. We would also like to acknowledge the assistance of Ethel $O$. Kouba, Ph.D., and Emilio H. Moriguchi, M.D., Ph.D., at the Bowman Gray School of Medicine (Winston-Salem, NC).

This work was supported by J. L. Breslow's National Institutes of Health grants R01 HL-32435, R01HL-33714, and P01 CA29502, the Calder Foundation, and R. B. Verdery's National Institutes of Health grant K01 AG00414.

\section{References}

1. Castelli, W. P., R. J. Garrison, P. W. F. Wilson, R. D. Abbott, S. Kalousdian, and W. B. Kannel. 1986. Incidence of coronary heart disease and lipoprotein cholesterol levels. J. Am. Med. Assoc. 256:2835-2838.

2. Gordon, D. J., J. Knoke, J. L. Probstfield, R. Superko, and H. A. Tyroler. 1986. High-density lipoprotein cholesterol and coronary heart disease in hypercholesterolemic men: the lipid research clinics coronary primary prevention trial. Circulation. 74:1217-1225.

3. Miller, N. E. 1987. Associations of high-density lipoprotein subclasses and apolipoproteins with ischemic heart disease and coronary atherosclerosis. $\mathrm{Am}$. Heart J. 113:589-597.

4. Gordon, D. J., and B. M. Rifkind. 1989. High-density lipoprotein. The clinical implications of recent studies. N. Eng. J. Med. 321:1311-1316.
5. Schaefer, E. J., R. I. Levy, N. D. Ernst, F. D. Van Sant, and H. B. Brewer. 1981. The effects of low cholesterol, high polyunsaturated fat, and low fat diets on plasma lipid and lipoprotein cholesterol levels in normal and hypercholesterolemic subjects. Am. J. Clin. Nutr. 34:1758-1763.

6. Blum, C. B., R. I. Levy, S. Eisenberg, M. Hall, R. H. Goebel, and M. Berman. 1977. High density lipoprotein metabolism in man. J. Clin. Invest. 60:795-807.

7. Shepherd, J., C. J. Packard, and J. R. Patsch. 1978. Effects of dietary polyunsaturated and saturated fat on the properties of high density lipoproteins and metabolism of apo A-I. J. Clin. Invest. 61:1582-1592.

8. Zanni, E. E., V. I. Zannis, C. B. Blum, P. N. Herbert, and J. L. Breslow. 1987. Effect of egg cholesterol and dietary fats on plasma lipids, lipoproteins, and apoproteins of normal women consuming natural diets. J. Lipid Res. 28:518527.

9. Brinton, E. A., S. Eisenberg, and J. L. Breslow. 1990. A low-fat diet decreases high density lipoprotein (HDL) cholesterol levels by decreasing HDL apolipoprotein transport rates. J. Clin. Invest. 85:144-151.

10. Walsh, A., Y. Ito, and J. L. Breslow. 1988. High levels of human apolipoprotein A-I in transgenic mice result in increased plasma levels of small high density lipoprotein (HDL) particles comparable to human $\mathrm{HDL}_{3}$. J. Biol. Chem. 264:6488-6494.

11. Rubin, E. M., B. Y. Ishida, S. M. Clift, and R. M. Krauss. 1991. Expression of human apolipoprotein A-I in transgenic mice results in reduced plasma levels of murine apolipoprotein A-I and the appearance of two new high density lipoprotein size subclasses. Proc. Natl. Acad. Sci. USA. 88:434-438.

12. Chajek-Shaul, T., T. Hayek, A. Walsh, and J. L. Breslow. 1991. Human apo A-I expression in transgenic mice alters HDL particle size distribution and diminishes selective uptake of HDL cholesteryl esters. Proc. Natl. Acad. Sci. USA. 88:6731-6735.

13. Hayek, T., T. Chajek-Shaul, A. Walsh, N. Azrolan, and J. L. Breslow. 1991. Probucol decreases apo A-I transport rate and increases HDL cholesteryl ester fractional catabolic rate in control and human apo A-I transgenic mice. Arterioscler. Thromb. 11:1295-1302.

14. LeBoeuf, R. C., M. H. Doolittle, A. Montcalm, D. C. Martin, K. Reue, A. J. Lusis. 1990. Phenotypic characterization of the Ath-1 gene controlling high density lipoprotein levels and susceptibility to atherosclerosis. J. Lipid Res. 31:91-101.

15. Ito, Y., L. C. Hudgins, J. Hirsch, and M. Shike. 1991. Adipose tissue fatty acid composition in recipients of long-term total parental nutrition (TPN). Am. J. Clin. Nutr. 53:1487-1492.

16. The Lipid Research Clinics Population Studies Data Book. 1982. The prevalence study: nutrient intake, Vol. II. U.S. Department of Health and Human Services, National Institutes of Health, Bethesda, MD. p. 42.

17. National Health and Nutrition Examination Survey. 1983. Dietary intake source data. National Center for Health Statistics, Office of Health Research Statistics and Technology. Hyattsville, MD. 48-52.

18. Denke, M. A., and J. L. Breslow. 1988. Effects of a low fat diet with and without intermittent saturated fat and cholesterol ingestion on plasma lipid, lipoprotein, and apolipoprotein levels in normal volunteers. J. Lipid Res. 29:963969.

19. Bilheimer, D. W., S. Eisenberg, and R. L. Levy. 1972. The metabolism of very low density lipoprotein proteins. Preliminary in vitro and in vivo observation. Biochim. Biophys. Acta. 260:212-221.

20. McFarlane, A. S. 1958. Efficient trace labeling of proteins with iodine Nature (Lond.). 182:53.

21. Hayek, T., T. Chajek-Shaul, A. Walsh, L. B. Agellon, P. Moulin, A. R. Tall, and J. L. Breslow. 1992. An interaction between the human cholesteryl ester transfer protein (CETP) and apolipoprotein A-I genes in transgenic mice results in a profound CETP mediated depression of high density lipoprotein cholesterol levels. J. Clin. Invest. 90:505-510.

22. Matthews, C. M. 1957. The theory of tracer experiments with ${ }^{131}$ I-labeled plasma proteins. Phys. Med. Biol. 2:36-53.

23. Blanche, P. J., E. L. Gong, T. M. Forte, and A. V. Nichols. 1981. Characterization of human high density lipoproteins by gradient gel electrophoresis. Biochim. Biophys. Acta. 665:408-418.

24. Verdery, R. B., D. F. Benham, H. L. Baldwin, A. P. Goldberg, and A. V. Nichols. 1989. Measurement of normative HDL subfraction cholesterol levels by Gaussian summation analysis of gradient gels. J. Lipid Res. 30:1085-1095.

25. Sparks, C. E., J. D. Sparks, D. Bolognino, A. Salhanick, P. S. Strumph, and J. M. Amatruda. 1986. Insulin effects on apolipoprotein B lipoprotein synthesis by primary cultures of rat hepatocytes. Metabolism. 35:1128-1136.

26. Williams, D. L., and P. A. Dawson. 1986. Immunochemical measurement of apolipoprotein synthesis in cell and organ culture. Methods Enzymol. 129:254-271.

27. Azrolan, N., and J. L. Breslow. 1990. A solution hybridization RNase protection assay with riboprobes to determine absolute levels of apo B, A-I, and E mRNA in human hepatoma cell lines. J. Lipid Res. 31:1141-1146.

28. Chomczynski, P., and N. Sacchi. 1987. Single-step method of RNA isolation by acid guanidinium thiocyanate-phenol-chloroform extraction. Anal. Biochem. 162:156-159. 
29. Tall, A. R. 1990. Plasma high density lipoproteins: Metabolism and relationship to atherogenesis. J. Clin. Invest. 86:379-384.

30. Eisenberg, S. 1984. High density lipoprotein metabolism. J. Lipid Res. 25:1017-1058.

31. Malloy, L. K., J. M. Van den Broek, A. Z. Loren, and C. C. Shwartz. 1990. HDL esterified cholesterol uptake by tissues is negligible in vivo in man. Circulation. 1771. (Abstr.)

32. Quig, D. W., and D. B. Zilversmit. 1989. High density lipoprotein metabolism in a rabbit model of hyperalphalipoproteinemia. Atherosclerosis. 76:9-19.

33. Sorci-Thomas, M., M. M. Prack, N. Dashti, F. Johnson, L. L. Rudel, D. L.

Williams. 1989. Differential effects of dietary fat on the tissue-specific expression of the apolipoprotein A-I gene: Relationship to plasma concentration of high density lipoproteins. J. Lipid Res. 30:1397-1403.

34. Srivastava, R. K., J. Tang, E. S. Krul, B. Pfleger, R. T. Kitchens, and G. Schonfeld. 1992. Dietary fatty acids and dietary cholesterol differ in their effect on the in vivo regulation of apolipoprotein A-I and A-II gene expression in inbred strains of mice. Biochim. Biophys. Acta. 1125:251-261.

35. Go, M. F., G. Schonfeld, B. Pfleger, T. G. Cole, N. L. Sussman, and D. H. Alpers. 1988. Regulation of intestinal and hepatic apoprotein synthesis after chronic fat and cholesterol feeding. J. Clin. Invest. 81:1615-1620.
36. Borchardt, R. A., and R. A. Davis. 1987. Intrahepatic assembly of very low density lipoproteins: Rate of transport out of the endoplasmic reticulum determines rate of secretion. J. Biol. Chem. 262:16394-16402.

37. McNerney, C. A., M. L. Kashyap, R. L. Barnhart, and R. L. Jackson. 1985. Comparison of gradient gel electrophoresis and zonal ultracentrifugation for quantitation of high density lipoproteins. J. Lipid Res. 26:1363-1367.

38. Brinton, E. A., S. Eisenberg, and J. L. Breslow. 1991. Increased apo A-I and apo A-II fractional catabolic rate in patients with low HDL-C levels with or without hypertriglyceridemia. J. Clin. Invest. 87:536-544.

39. Brinton, E. A., S. Eisenberg, and J. L. Breslow. 1989. Elevated HDL-C levels correlate with decreased apo A-I and apo A-II fractional catabolic rate in women. J. Clin. Invest. 84:262-269.

40. Horowitz, B. S., I. J. Goldberg, J. Merab, T. M. Vanni, R. Ramakrishnan, and H. N. Ginsberg. 1992. Increased plasma and renal clearance of an exchangeable pool of apolipoprotein A-I in subjects with low levels of high density lipoprotein cholesterol. J. Clin. Invest. In press.

41. Miller, J. C., R. K. Barth, P. H., Shaw, R. W. Elliott, and N. D. Hastie. 1983. Identification of a cDNA clone for mouse apoprotein A-I (apo A-I) and its use in characterization of apo A-I mRNA expression in liver and small intestine. Proc. Natl. Acad. Sci. USA. 80:1511-1515. 